\title{
BMJ Open Determinants of timeliness in early childhood vaccination among mothers with vaccination cards in Sindh province, Pakistan: a secondary analysis of cross-sectional survey data
}

\author{
Jin-Won Noh, ${ }^{1,2}$ Young-mi Kim, ${ }^{3}$ Nabeel Akram, ${ }^{3}$ Ki Bong Yoo, ${ }^{\odot}$ \\ Jooyoung Cheon, ${ }^{5}$ Lena J Lee, ${ }^{6}$ Young Dae Kwon, ${ }^{\oplus 7}$ Jelle Stekelenburg ${ }^{2,8}$
}

To cite: Noh J-W, Kim Y, Akram N, et al. Determinants of timeliness in early childhood vaccination among mothers with vaccination cards in Sindh province, Pakistan: a secondary analysis of cross-sectional survey data. BMJ Open 2019;9:e028922. doi:10.1136/ bmjopen-2019-028922

\section{- Prepublication history for} this paper is available online. To view these files, please visit the journal online (http://dx.doi org/10.1136/bmjopen-2019028922).

Received 03 January 2019 Revised 21 August 2019 Accepted 05 September 2019

Check for updates

(C) Author(s) (or their employer(s)) 2019. Re-use permitted under CC BY-NC. No commercial re-use. See rights and permissions. Published by BMJ.

For numbered affiliations see end of article.

Correspondence to Dr Young Dae Kwon; snukyd1@naver.com

\section{ABSTRACT}

Objective Untimely vaccination refers to receiving the given dose before (early) or after (delayed) the recommended time window. The purpose of this study was to assess the extent of timeliness of childhood vaccinations and examine the determinants of vaccination timeliness in Sindh province, Pakistan.

Design Cross-sectional analysis of data from the 2013 and 2014 Maternal and Child Health Program Indicator Surveys. Setting Community-based maternal and child health surveys.

Participants Among 10200 respondents of Maternal and Child Health Program Indicator Surveys, 1143 women who had a live birth in the 2 years preceding the survey were included.

Outcomes At the participants' home, an interviewer asked mothers to show their children's vaccination cards, which contained information regarding vaccinations. Children's vaccination status was categorised into timely or early/delayed compared with vaccination schedule. A logistic regression analysis using Firth's penalised likelihood was performed to identify factors associated with timeliness of vaccinations.

Results 238 children (20.8\% of children who received a full set of basic vaccinations) received all vaccinations on schedule among children who received a full set of basic vaccinations. The percentages of timely vaccinations ranged from $2.3 \%$ for second measles vaccination to $89.3 \%$ for bacillus Calmette-Guérin. Child's age and place of delivery were associated with timely vaccinations. Older child age and institutional delivery were associated with decreased timely vaccination rate.

Conclusions Home-based vaccination record is a key tool to improve the timeliness of vaccinations. The redesigned vaccination cards, the new electronic registries for vaccination card information and the vaccination tracking system to remind the second/third vaccination visits may be helpful to improve timely vaccinations for children under 2 years old.

\section{INTRODUCTION}

Achieving high vaccination coverage is crucial in the control and prevention of childhood as
Strengths and limitations of this study

- This study is the first study to examine the timeliness of childhood vaccination coverage and its determinants in Sindh province, Pakistan.

- We used vaccination card to get information and then categorised each child's vaccination status into timely or early/delayed.

- The $\chi^{2}$ test was used to determine if a statistically significant relationship and binary logistic regression analysis was performed to identify factors associated with timeliness of vaccination.

- This is a cross-sectional study, and samples were selected using a multistage, stratified, sampling design.

- A possible limitation of this study is restricted to one province, Sindh, in Pakistan, so the study findings might not be generalisable to all regions.

well as older age infections. Currently, standard estimates of vaccination coverage are based on vaccination statuses at predefined ages, typically at 12 months, 24 months and 4-6years. The most widely accepted indicator internationally is the proportion of children who have received recommended routine vaccinations by 24 months of age, as prescribed by the WHO. ${ }^{12}$ This indicator does not measure delays in the acquisition of immunity caused by late vaccination. ${ }^{3}$

The timeliness of immunisations, that is, receiving vaccinations at the earliest appropriate age, is an important public health goal for several reasons. First, if children are vaccinated too early or if vaccinations are too closely spaced, it can significantly shorten the duration of protection or interfere with the body's immune response. ${ }^{4}$ Second, delayed immunisation potentially leads to prolonged exposure to vaccine-preventable diseases. ${ }^{5}$ In 
addition, timely vaccination heightens populations' herd immunity levels, ${ }^{6}$ thereby protecting those who are too young to be vaccinated, those who have medical contraindications and those who do not produce an adequate immunological response. Despite the importance of the timeliness of childhood immunisations, vaccination delays are prevalent across lower income countries, including Pakistan. An analysis of the 2006-2007 Pakistan Demographic and Health Survey found substantial variations in the timeliness of vaccinations, including considerable delays in many cases. ${ }^{7}$

Factors associated with lack of childhood vaccination have been studied extensively, and specific patterns have been identified.$^{8-11}$ In contrast, less is known about factors associated with delayed vaccination and whether these factors follow the same patterns in different societies. ${ }^{12-15}$ Information about factors that influence the timeliness of childhood vaccination might be valuable for healthcare providers, programme managers and policymakers in identifying sub-populations at risk, which should be targeted with interventions and public health policies. ${ }^{16}$ The timeliness of childhood vaccination has received close attention in the USA and in Europe, ${ }^{8}$ but in-depth investigations in low-income countries have been limited, particularly in Pakistan. The purpose of this study was to examine the timeliness of childhood vaccination coverage and its determinants in Sindh province, Pakistan.

\section{METHODS}

\section{Data and subjects}

This study analysed a subset of data from the Maternal and Child Health Program Indicator Survey, which was conducted in June to October of 2013 and 2014 in 23 districts of Sindh province and Karachi in Pakistan. ${ }^{17}$ The survey was a cross-sectional study, and samples were selected using a stratified multistage sampling design. Survey respondents included 4000 women in 2013 and 6200 women in 2014 who had a live birth in the 2 years preceding the survey. Women answered questions about maternal and child health $(\mathrm{MCH})$ related to their last live birth. The inclusion criterion of this analysis was the respondents who answered all variables of interest and who presented a vaccination card to the data collector. The vaccination card is a home-based record (HBR), which documents immunisation status in developing countries. ${ }^{18}$ It contains each child's specific vaccination information, including child's name, birthdate, type of vaccination and vaccination date. It is issued to each child at its first vaccination.

Seven thousand eight hundred and forty $(76.9 \%$ of total survey respondents) women were excluded due to not having vaccination cards or to missing information on their vaccination cards. An additional 107 women were excluded because they were missing information on the number of living children $(\mathrm{n}=1)$, woman's education $(\mathrm{n}=6)$, husband's education $(\mathrm{n}=15)$, household wealth $(\mathrm{n}=11)$ or antenatal care $(\mathrm{ANC})$ visit $(\mathrm{n}=74)$. Women with

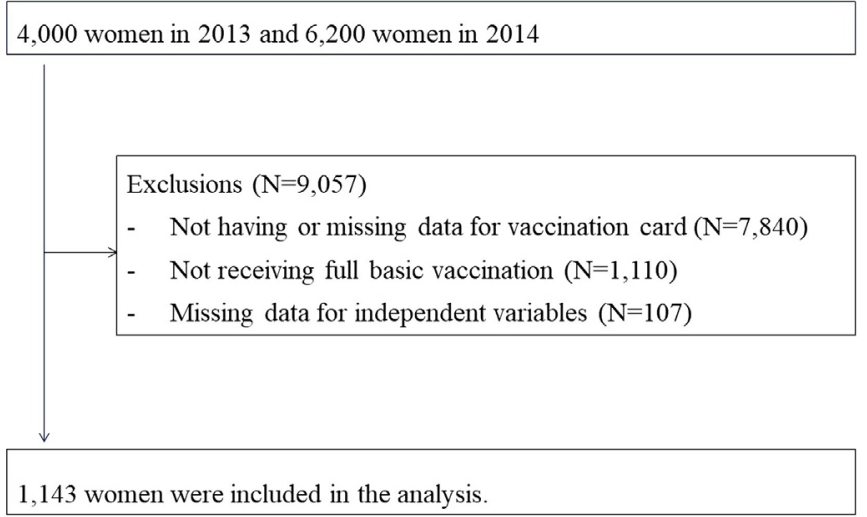

Figure 1 Flowchart showing study population selection.

children who did not receive a full set of basic vaccinations $(n=1110)$ were also excluded. Finally, a total of 1143 women who had all the information needed for analysis and whose children received a full set of basic vaccinations were included in this study (figure 1). It was 11.2\% of total survey respondents.

As female literacy is low in Sindh province, female interviewers obtained verbal informed consent from each respondent and then signed the consent form on behalf of the respondent.

\section{Patient and public involvement}

This research was done without patient involvement. Patients were not invited to comment on the study design and were not consulted to develop patient relevant outcomes or interpret the results. Patients were not invited to contribute to the writing or editing of this document for readability or accuracy.

\section{Measurement for timeliness in vaccination}

From the vaccination card, we collected information and then categorised each child's vaccination status into timely or early/delayed. The definitions of timely and early/delayed vaccinations followed those used in Zaidi et $a l^{7}$ The measles 2 schedule, which was not included in the study by Zaidi $e t a l$, was updated using a report by $\mathrm{Khan}^{19}$ and the WHO recommendation. ${ }^{1}$ Our definition of timely and early/delayed vaccination is shown in table 1 .

Children who had received all appropriate vaccinations on schedule were put into the 'timely' vaccination group. If children received all appropriate vaccinations for their age, but one or more vaccinations were not administered on time, they were put into the 'early or delayed' group. We combined children who received vaccinations early and those who received vaccinations late into one group due to a small number, and both eventualities cause timely vaccination problems. ${ }^{2021}$

\section{Independent variables}

To identify the determinants of timely vaccination, our analysis included the following independent variables: child's age, woman's age, number of living children, 
Table 1 The definition of early, timely and delayed for each vaccine

\begin{tabular}{lllll}
\hline & Recommended age (days) & Early (days) & Timely (days) & $\begin{array}{l}\text { Delayed } \\
\text { (days) }\end{array}$ \\
\hline BCG, polio 0 & 0 & - & $0-28$ & $>28$ \\
Polio 1, penta 1 & 42 & $<39$ & $39-70$ \\
Polio 2, penta 2 & 70 & $<67$ & $67-98$ & $>70$ \\
Polio 3, penta 3 & 98 & $<95$ & $95-126$ \\
Measles 1 & 273 & $<270$ & $270-301$ & $>126$ \\
Measles 2 & $365-455$ & $<$ Min (28 days from & Min (28 days from \\
& & measles 1 or 362) & measles 1 or 362) \\
\hline
\end{tabular}

Authors edited this table with the articles of $\mathrm{WHO},{ }^{1}$ Zaidi et $\mathrm{al}^{7}$ and $\mathrm{Khan}^{19}$

residence, woman's education, husband's education, wealth quintile, information source about $\mathrm{MCH}$, number of ANC visits, assistance during delivery and place of delivery. Previous studies of a similar type conducted in Pakistan and other low/middle-income countries included the same variables. ${ }^{7917}$

Categories of independent variables followed the Maternal and Child Health Program Indicator Survey report ${ }^{17}$ Wealth quintile was derived from household assets using a principal components analysis, as described previously. ${ }^{22}$ To identify MCH information sources, interviewers asked: 'During the last 12 months, have you received any information about $\mathrm{MCH}$ from the following sources?'. Sources were categorised as medical professionals (doctors, nurse/midwives and female health visitors), low-level health workers (Dai-traditional birth attendants, female health workers, homeopaths, Hakimherbal medicine practitioners and outreach workers), relatives/friends and media (radio, TV, telephone helpline, text message on mobile phone, health education/ awareness session and print media). As multiple answers were permitted, answers per category were included in our model. The number of ANC visits was categorised into ' 1 ' or ' 2,3 ' and ' $4+$ '. Assistance during delivery was categorised into traditional birth attendants, medical professionals and no one/others. Place of delivery was categorised into home, private facility and public facility.

\section{Statistical analysis}

The $\chi^{2}$ test was used to determine if a statistically significant relationship existed between each independent variable and timeliness of vaccination. Then, binary logistic regression analysis was performed to identify factors associated with timeliness of vaccination. A binary logistic regression analysis was conducted for early or delayed (reference) versus timely vaccination. Because the number of events were low, logistic regression using Firth's penalised likelihood was conducted in this study. ${ }^{23}$ The criterion for significance was $\mathrm{p} \leq 0.05$, two-tailed. ORs and $95 \%$ CIs were calculated. ORs were calculated after adjusting for all independent variables. All analyses were performed using SAS V.9.4.

\section{RESULTS}

The general characteristics of the study subjects are shown in table 2: 238 children (20.8\%) received all vaccinations on schedule, while 905 children $(79.1 \%)$ received all vaccinations, but some or all were early or delayed. The rate of early and delayed vaccinations increased as children got older, being $5.6 \%$ in children aged $0-5$ weeks and increasing to $100.0 \%$ in the oldest children (12-23 months) (table 2).

The timeline of vaccinations is presented in table 3 . The percentage of children with timely vaccinations was $89.3 \%$ for bacillusCalmette-Guérin (BCG) and $87.7 \%$ for polio 0 ; all other rates of timely vaccinations were lower. Due to early vaccination, the number of subjects was more than the eligible number of subjects. The percentage of delayed vaccinations increased for polio 3 and penta 3 in children aged 14 weeks to 8 months. The percentage of delayed vaccinations for penta 3 was $43.4 \%$, which was the highest among all vaccines. Over $90 \%$ of children in this study received measles 1-2 earlier than the recommended timeframe (table 3 ).

Table 4 shows the factors associated with timely vaccination. As children aged, the timeliness of vaccination decreased. Children 70-97 days old were less likely to receive timely vaccinations $(\mathrm{OR}=0.12 ; 95 \%$ CI 0.04 to 0.36$)$ compared with children 0-69 days old. The OR became 0.02 (95\% CI 0.01 to 0.04 ) for children 98 days or older. With regard to place of delivery, compared with home deliveries, deliveries in both private facilities $(\mathrm{OR}=0.39$; 95\% CI 0.17 to 0.96 ) and public facilities ( $\mathrm{OR}=0.34$; $95 \%$ CI 0.14 to 0.89 ) showed significantly lower ORs for timely vaccinations (table 4 ).

\section{DISCUSSION}

In Pakistan, the vaccination rates for the full set of basic vaccines has been increasing due to the expanded programme on immunisation (EPI), but little is known about the vaccination timeliness and the determinants for early, timely and delayed vaccination. The present study aimed to assess the extent of timeliness of childhood 
Table 2 General characteristics of the study population

\begin{tabular}{|c|c|c|c|c|c|c|}
\hline \multirow[b]{2}{*}{ Variable } & \multirow[b]{2}{*}{ Category } & \multicolumn{2}{|c|}{$\begin{array}{l}\text { Early/delayed, but complete } \\
\text { vaccination }(n=905)\end{array}$} & \multicolumn{2}{|c|}{$\begin{array}{l}\text { Timely and complete } \\
\text { vaccination }(n=238)\end{array}$} & \multirow{2}{*}{$\begin{array}{l}\begin{array}{l}\text { Total } \\
(n=1143)\end{array} \\
n\end{array}$} \\
\hline & & $n$ & $\%$ & $n$ & $\%$ & \\
\hline \multirow[t]{6}{*}{ Child's age (days) } & $0-41$ & 4 & 5.6 & 63 & 94.0 & 67 \\
\hline & $42-69$ & 9 & 22.0 & 32 & 78.1 & 41 \\
\hline & $70-97$ & 10 & 52.6 & 9 & 47.4 & 19 \\
\hline & $98-272$ & 237 & 64.6 & 130 & 35.4 & 367 \\
\hline & $273-365$ & 226 & 98.3 & 4 & 1.7 & 230 \\
\hline & $365-$ & 419 & 100.0 & 0 & 0 & 419 \\
\hline \multirow[t]{3}{*}{ Woman's age (years) } & $15-24$ & 294 & 78.4 & 81 & 21.6 & 375 \\
\hline & $25-34$ & 516 & 79.9 & 130 & 20.1 & 646 \\
\hline & $35+$ & 95 & 77.9 & 27 & 22.1 & 122 \\
\hline \multirow[t]{5}{*}{ No of living children } & 1 & 246 & 78.9 & 66 & 21.2 & 312 \\
\hline & 2 & 246 & 80.4 & 60 & 19.6 & 306 \\
\hline & 3 & 149 & 77.6 & 43 & 22.4 & 192 \\
\hline & 4 & 105 & 79.0 & 28 & 21.1 & 133 \\
\hline & $5+$ & 159 & 79.5 & 41 & 20.5 & 200 \\
\hline \multirow[t]{3}{*}{ Residence } & Rural & 270 & 82.6 & 57 & 17.4 & 327 \\
\hline & Town/small city & 319 & 77.2 & 94 & 22.8 & 413 \\
\hline & Large city & 316 & 78.4 & 87 & 21.6 & 403 \\
\hline \multirow[t]{3}{*}{ Woman's education } & No education & 328 & 79.4 & 85 & 20.6 & 413 \\
\hline & $\begin{array}{l}\text { Primary or middle } \\
\text { school }\end{array}$ & 267 & 82.2 & 58 & 17.9 & 325 \\
\hline & $\begin{array}{l}\text { Secondary school } \\
\text { or higher }\end{array}$ & 310 & 76.5 & 95 & 23.5 & 405 \\
\hline \multirow[t]{3}{*}{ Husband's education } & No education & 195 & 79.0 & 52 & 21.1 & 247 \\
\hline & $\begin{array}{l}\text { Primary or middle } \\
\text { school }\end{array}$ & 208 & 83.2 & 42 & 16.8 & 250 \\
\hline & $\begin{array}{l}\text { Secondary school } \\
\text { or higher }\end{array}$ & 502 & 77.7 & 144 & 22.3 & 646 \\
\hline \multirow[t]{5}{*}{ Wealth quintiles } & First (poorest) & 49 & 83.1 & 10 & 17.0 & 59 \\
\hline & Second & 99 & 79.8 & 25 & 20.2 & 124 \\
\hline & Third & 200 & 80.7 & 48 & 19.4 & 248 \\
\hline & Fourth & 243 & 78.6 & 66 & 21.4 & 309 \\
\hline & Fifth (richest) & 314 & 77.9 & 89 & 22.1 & 403 \\
\hline \multicolumn{7}{|l|}{$\mathrm{MCH}$ information source } \\
\hline \multirow[t]{2}{*}{ Medical professional } & No & 367 & 76.8 & 111 & 23.2 & 478 \\
\hline & Yes & 538 & 80.9 & 127 & 19.1 & 665 \\
\hline \multirow[t]{2}{*}{ Low-level health workers* } & No & 805 & 79.1 & 210 & 20.7 & 1015 \\
\hline & Yes & 100 & 78.1 & 28 & 21.9 & 128 \\
\hline \multirow[t]{2}{*}{ Relatives/friends } & No & 363 & 76.6 & 111 & 23.4 & 474 \\
\hline & Yes & 542 & 81.0 & 127 & 19.0 & 669 \\
\hline \multirow[t]{2}{*}{ Media } & No & 575 & 79.2 & 151 & 20.8 & 726 \\
\hline & Yes & 330 & 79.1 & 87 & 20.9 & 417 \\
\hline \multirow[t]{3}{*}{ No of antenatal care visits } & $1-2$ & 132 & 83.5 & 26 & 16.5 & 158 \\
\hline & 3 & 128 & 77.6 & 37 & 22.4 & 165 \\
\hline & $4+$ & 645 & 78.7 & 175 & 21.3 & 820 \\
\hline
\end{tabular}




\begin{tabular}{|c|c|c|c|c|c|c|}
\hline \multirow[b]{2}{*}{ Variable } & \multirow[b]{2}{*}{ Category } & \multicolumn{2}{|c|}{$\begin{array}{l}\text { Early/delayed, but complete } \\
\text { vaccination }(n=905)\end{array}$} & \multicolumn{2}{|c|}{$\begin{array}{l}\text { Timely and complete } \\
\text { vaccination }(n=238)\end{array}$} & \multirow{2}{*}{$\begin{array}{l}\begin{array}{l}\text { Total } \\
(n=1143)\end{array} \\
n \\
\end{array}$} \\
\hline & & $\mathbf{n}$ & $\%$ & $\mathbf{n}$ & $\%$ & \\
\hline \multirow[t]{3}{*}{ Assistance during delivery } & $\begin{array}{l}\text { Traditional birth } \\
\text { attendant }\end{array}$ & 168 & 82.8 & 35 & 17.2 & 203 \\
\hline & $\begin{array}{l}\text { Medical } \\
\text { professional }\end{array}$ & 733 & 78.5 & 201 & 21.5 & 934 \\
\hline & No one/others & 4 & 66.7 & 2 & 33.3 & 6 \\
\hline \multirow[t]{3}{*}{ Place of delivery } & Home & 187 & 79.2 & 49 & 20.8 & 236 \\
\hline & Private facility & 557 & 78.6 & 152 & 21.4 & 708 \\
\hline & Public facility & 161 & 81.3 & 37 & 18.7 & 198 \\
\hline
\end{tabular}

*Low-level health workers, including Dai-traditional birth attendants, female health workers, homeopaths, Hakim-herbal medicine practitioners and outreach workers.

BCG, bacillus Calmette-Guérin; $\mathrm{MCH}$, maternal and child health.

vaccinations and found two critical issues related to the reliable estimates.

In this study, $7840(76.9 \%)$ women did not have vaccination cards or missed information on their vaccination cards in the dataset from the Maternal and Child Health Program Indicator Survey in 2013-2014, which might have overestimated or underestimated the vaccination status. Only $23.1 \%$ of total survey respondents were included in this analysis. According to the WHO guidance on vaccination coverage surveys, the survey can rely on HBRs as an important, effective, inexpensive source of documented evidence of vaccination history. ${ }^{18}$ A systematic review found that there was relatively good agreement between vaccination based on documented evidence in HBRs and that obtained from maternal/caregiver recalls, but comparatively poor agreement versus facility-based records. ${ }^{24}$ HBRs are a key tool to let families know when the child needs to go back for their next vaccine, however, in Pakistan, current HBR prevalence was $36 \%$ and HBR loss rate was $52 \%$ in 2012 , which reflect that Pakistan has HBRs access problems. ${ }^{25}{ }^{26}$ Therefore, it is necessary to conduct large nationally representative surveys or to introduce the electronic system such as m-health for improving the vaccination information and vaccination uptake. ${ }^{27} 28$

Another issue in this study was that there is no global consensus on the definitions of timely, early and delayed vaccinations between governments, organisations and researchers. For example, recommended and minimum acceptable ages and intervals for routine vaccinations differed between the Centers for Disease Control and Prevention in the USA, ${ }^{29}$ the Pan American Health Organization ${ }^{30}$ and a study of Zaidi $e t a l$ in Pakistan. ${ }^{7}$ Vaccine doses administered $\leq 4$ days before the minimum interval or age are considered valid in the USA, whereas Zaidi et al defined as 'early' if there were administered 3 days prior to the recommended age. ${ }^{729}$ The uniform global and national guideline for recommended and minimum ages and intervals between vaccine doses are required to enable consistent and comparable measurement of adherence to the guideline. One uniform guideline would improve timely complete immunisation of infants regardless of their country and would help infants to receive recommended vaccine doses, which may prevent side effects from overdose vaccination or reduce the risk of vaccine-preventable diseases from underdosing. ${ }^{31}$

In this study, only 238 children (20.8\%) received a full set of vaccinations on schedule in the Sindh province of Pakistan. Determinants for receiving timely vaccinations were the child's age and the place of delivery. The proportion of children who had not received age-appropriate vaccinations increased with age, which was consistent with the findings of a previous study using 2006-2007 Pakistan Demographic and Health Survey data. ${ }^{7}$ In that study, the proportions of children who had early immunisations were $19.9 \%$ for the first vaccination for polio1 and penta, and these proportions progressively decreased by $11.2 \%$ in polio $3 \%$ and $11.4 \%$ in penta 3 . Correspondingly, the proportions of delayed immunisations progressively increased by $42.6 \%$ in polio 3 and by $43.4 \%$ in penta 3 . One possible reason for the early/delayed vaccination may be that the mothers were reminded of the importance of vaccinations for children due to the efforts by the EPI programme and the government of Pakistan and, as a result, had their children vaccinated at birth, but had difficulty remembering and/or complying to vaccination appointments over time due to other family/social activities, lost or misplaced vaccination cards and lack of an institutional vaccination monitoring system giving reminders for second/third vaccines. ${ }^{2}{ }^{25} 32$ Therefore, a considerable proportion of children in Pakistan do not receive a timely, full set of vaccinations, placing them at risk of vaccine-preventable diseases such as meningitis, diarrheal disease and pneumonia as the main causes of death in children under 5 years old in Pakistan. ${ }^{33}$

Even though there has been no study to describe the reasons that children do not receive timely vaccinations in Pakistan, a systematic review indicated that out-of-hospital 
delivery and a lack of reminders about the next follow-up visit required for vaccinations were associated with delayed vaccination in low-income countries. ${ }^{24}$ Therefore, a tracking systems for health workers to provide correct information about vaccines and immunisation may be helpful to improve timely and complete vaccination of children. Tracking systems are also necessary to ensure that children do not drop out of the system once they have begun the vaccination series. A randomised, controlled trial in rural peripheries of Karachi, Pakistan found that the redesigned vaccination cards were effective in helping women and children achieve in a timely manner the third dose of diphtheria-tetanus-pertussis (DTP3) immunisation. ${ }^{34}$ The redesigned card was a bright colour, placed in a plastic jacket, provided with a hanging string and showed the immunisation date for the DTP2 and DTP3 visits written in a large font and information about the EPI centres for women. In another study in Karachi, Pakistan, ${ }^{35}$ every infant received three activated vaccine indicator and reminder (VIR) bands for each visit, and secured to their ankle. When the VIR bands' timestrip membrane turned completely different colour, parents could know it is time to visit the vaccination centre. At the fourth visit, digital vaccine registry for all infants was created and updated during each immunisation visit. The results showed more than $86 \%$ retention of the VIR band at each vaccination visit and $62 \%$ of infants completed penta 3. Further interventions regarding the redesigned HBRs, such as photographing cards, VIR bands and setting electronic collection formats and platforms to register HBRs information are required to improve the timeliness of childhood vaccinations. ${ }^{1824} 3435$

In our study, $>10 \%$ of children did not receive BCG and polio 0 in time. Previous studies of the non-specific effects of the BCG vaccine and oral polio vaccine (OPV) within the first 2 days of life indicated that those vaccines might reduce the risk of all-cause mortality. ${ }^{37}$ Administration of the BCG and polio vaccines timely may stimulate children's immune systems, which may lead to a decrease in mortality as a result of other infectious diseases. In previous studies, delays in the first polio and DTP vaccinations led to delays in the second and third vaccinations in the series, which indicated that these children remained vulnerable to vaccine-preventable diseases. ${ }^{70} 3438$ Unfortunately, there has been no study to examine the factors influencing delays in BCG and OPV vaccinations in Pakistan. Further studies should determine the factors that impede timely vaccinations in Pakistan to prevent exposure of children to vaccine-preventable diseases at birth and to develop interventions to improve the rates of BCG and OPV vaccinations in Pakistan.

Interestingly, most children had early vaccination for measles 1 and 2 in this study, at rates that were dramatically higher than the early vaccination rates of previous studies. ${ }^{87}$ One possible explanation is that the measles outbreaks started in December 2012 in Sindh province which killed 360 children in 2012-2013. ${ }^{39} 40$ The provincial Ministry of Health conducted a large vaccination 
Table 4 Factors associated with timely vaccination

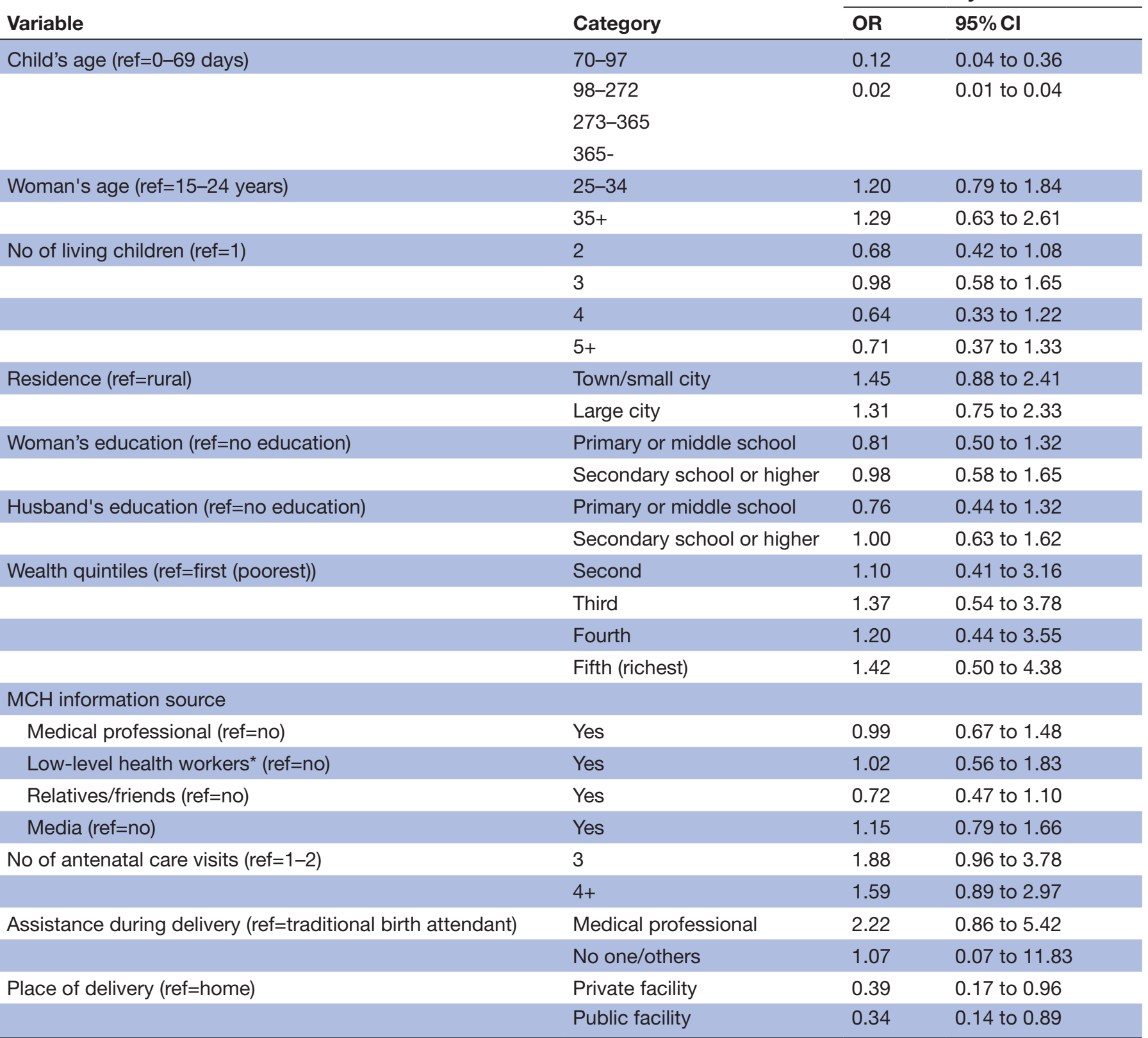

*Low-level health workers, including Dai-traditional birth attendants, female health workers, homeopaths, Hakim-herbal medicine practitioners and outreach workers.

†All independent variables were adjusted.

$\mathrm{MCH}$, maternal and child health; ref, reference.

campaign targeting 2.9 million children in Sindh between 31 December 2012 and 9 January 2013. As a result, 1.3 million children aged 9 months to 10 years were vaccinated, ${ }^{37}$ which may have contributed to the increased early vaccination rates in 2013-2014.

A previous study reported that institutional delivery was a positive determinant for full childhood vaccination ${ }^{2}{ }^{32}$; however, in the present study, children who were born in public and private facilities were less likely to receive timely vaccinations compared with those who were born at home.
In many cases, children received vaccinations at the place they were born. When they deliver in facilities, mothers may try to have their babies receive all possible vaccines even if it is not the right time for vaccinations, due to limited access to healthcare services. ${ }^{41}{ }^{42}$ Therefore, the accessibility issue may have affected the result. Unfortunately, there has been no study to describe how and when children are given vaccines and who gives vaccines to children under 2 years old who were born in the public or the private facilities in Pakistan. Therefore, further studies should be conducted 
to determine the reasons why institutional delivery was associated with early or delayed vaccination among children under 2years old and to develop intervention programme to improve timely vaccination rates among children who are born in institutions.

This study has several limitations. First, it was restricted to one province, Sindh, in Pakistan, so the study findings might not be generalisable to all regions because there is a wide regional demographic variation in Pakistan. Second, study participants were limited to mostly women who had vaccination cards; therefore, the vaccination coverage rates and vaccination timeliness might have been overestimated in this study population compared with the general population, because they are more likely to have taken their children for vaccinations than other women who cannot present cards. However, as our variable of interest was vaccination status, we excluded those who did not have a vaccination card or who could not present a vaccination card. Reviewing the vaccination card is currently the only way to analyse children's vaccination status and date in Pakistan. Also, most studies $(49 / 62,79 \%)$ used data from vaccination cards, according to the systematic review of vaccination status. ${ }^{28}$ Finally, other possible determinants of timely vaccination, such as the number of facility visits, previous experience of healthcare service use, and distance from a health facility or having transportation options/alternatives, were not included in this study.

Despite these limitations, this study is the first to identify the determinants of timely vaccination among children aged 0-23 months in Sindh Province, Pakistan. In this study, two-thirds of women did not have vaccination cards or missed information on their vaccination cards. Therefore, vaccination programme managers should monitor HBR prevalence and the causes which lead to women not having cards or missed vaccinations on the cards, and should identify solutions to increase current HBR prevalence. To improve timely vaccination rates, the redesigned HBRs, the new electronic collection formats and platforms to register HBRs information, and a vaccination tracking system for health workers that provides information about age-appropriate vaccinations and appropriate follow-up vaccinations for children under 2 years old may be helpful for women and children, to achieve herd immunity for vaccine-preventable diseases. In addition, it is necessary to conduct large nationally representative surveys about vaccination. To improve timeliness, it is necessary to not only understand factors associated with timeliness (or un-timeliness) well but also do a root-cause analysis and identify the evidence around interventions. Also, future investigators should determine the inhibiting factors for timely vaccinations and the factors related to the utilisation of follow-up vaccine doses, and develop intervention programme to improve timely vaccinations for children who were born in institutions.

\section{Author affiliations}

${ }^{1}$ Department of Health Administration, Dankook University, Cheonan, Korea (the Republic of)
${ }^{2}$ Global Health Unit, Department of Health Sciences, University Medical Centre Groningen, University of Groningen, Groningen, The Netherlands

${ }^{3}$ Jhpiego, Johns Hopkins University, Baltimore, Maryland, USA

${ }^{4}$ Department of Health Administration, Department of Information \& Statistics, Yonsei University, Wonju, Korea (the Republic of)

${ }^{5}$ College of Nursing, Sungshin Women's University, Seongbuk-gu, Korea (the Republic of)

${ }^{6}$ National Institutes of Health Clinical Center, National Institutes of Health, Bethesda, Maryland, USA

${ }^{7}$ Department of Humanities and Social Medicine, Catholic University of Korea College of Medicine, Seoul, Korea (the Republic of)

${ }^{8}$ Obstetrics and Gynaecology, Medisch Centrum Leeuwarden, Leeuwarden, The Netherlands

Contributors J-WN, Y-mK, YDK and JS conceptualised and designed the study J-WN, Y-mK, NA, YDK and JS wrote up the results and revised the manuscript. $J$-WN and KBY cleaned and analysed the data and wrote sections of the manuscript. JC and LJL reviewed the literature, interpreted the findings and wrote sections of the manuscript.

Funding This publication was made possible through support provided by the US Agency for International Development (USAID), under the terms of Associate Cooperative Agreement No. AID-391-LA-13- 00001; Maternal, Newborn and Child Health Services Project.

Competing interests None declared.

Patient consent for publication Not required.

Ethics approval The study has been performed with approval of the Institutional Review Board at Johns Hopkins University School of Public Health (IRB00005002) and the National Bioethics Committee of Pakistan.

Provenance and peer review Not commissioned; externally peer reviewed. Data availability statement No data are available.

Open access This is an open access article distributed in accordance with the Creative Commons Attribution Non Commercial (CC BY-NC 4.0) license, which permits others to distribute, remix, adapt, build upon this work non-commercially, and license their derivative works on different terms, provided the original work is properly cited, appropriate credit is given, any changes made indicated, and the use is non-commercial. See: http://creativecommons.org/licenses/by-nc/4.0/.

\section{REFERENCES}

1. World Health Organization (WHO). Who recommendations for routine immunization-summary tables, 2019. Available: https://www.who.int/ immunization/policy/immunization_tables/en/

2. Tauil MdeC, Sato APS, Waldman EA. Factors associated with incomplete or delayed vaccination across countries: a systematic review. Vaccine 2016;34:2635-43.

3. Hull BP, Mclntyre PB. Timeliness of childhood immunisation in Australia. Vaccine 2006;24:4403-8.

4. Plotkin SA, Plotkin SA. Vaccines: correlates of vaccine-induced immunity. Clin Infect Dis 2008;47:401-9.

5. Hosseinpoor AR, Victora C, Bergen N, et al. Towards universal health coverage: the role of within-country wealth-related inequality in 28 countries in sub-Saharan Africa. Bull World Health Organ 2011;89:881-90.

6. Fine P, Eames K, Heymann DL. "Herd immunity": a rough guide. Clin Infect Dis 2011;52:911-6.

7. Zaidi SMA, Khowaja S, Dharma K V, et al. Coverage, timeliness, and determinants of immunization completion in Pakistan: evidence from the demographic and health survey (2006-07). Hum Vaccin Immunother 2014;10:1712-20.

8. Curran D, Terlinden A, Poirrier J-E, et al. Vaccine timeliness: a cost nalysis of the potential implications of delayed pertussis vaccination in the US. Pediatr Infect Dis J 2016;35:542-7.

9. Rainey JJ, Watkins M, Ryman TK, et al. Reasons related to nonvaccination and under-vaccination of children in low and middle income countries: findings from a systematic review of the published literature, 1999-2009. Vaccine 2011;29:8215-21.

10. Bosch-Capblanch X, Banerjee K, Burton A. Unvaccinated children in years of increasing coverage: how many and who are they? Evidence from 96 low- and middle-income countries. Trop Med Int Health 2012;17:697-710. 
11. Favin M, Steinglass $R$, Fields $R$, et al. Why children are not vaccinated: a review of the grey literature. Int Health 2012;4:229-38.

12. Yu Hu, Qian Li, Chen Y, et al. Timeliness of childhood primary immunization and risk factors related with delays: evidence from the 2014 Zhejiang provincial vaccination coverage survey. Int J Environ Res Public Health 2017;14:1086.

13. Mbengue MAS, Mboup A, ID L, et al. Vaccination coverage and immunization timeliness among children aged 12-23 months in Senegal: a Kaplan-Meier and COX regression analysis approach. Pan Afr Med J 2017;27(Suppl 3).

14. Sheikh N, Sultana M, Ali N, et al. Coverage, timelines, and determinants of incomplete immunization in Bangladesh. TropicalMed 2018;3.

15. Zivich PN, Kiketa L, Kawende B, et al. Vaccination coverage and Timelines among children 0-6 months in Kinshasa, the Democratic Republic of Congo: a prospective cohort study. Matern Child Health J 2017;21:1055-64.

16. World Health Organization (WHO). Immunization leaders call for increased political support for immunization in Pakistan, 2015. Available: http://www.emro.who.int/media/news/political-supportimmunization-pakistan.html

17. Agha S, Williams E. Maternal and Child Health (MCH) Program Indicator Survey 2013, Sindh Province. In: MNCH services component, USAID/Pakistan MCH program. Karachi, Pakistan: Jhpiego, 2013.

18. Danovaro-Holliday MC, Dansereau E, Rhoda DA, et al. Collecting and using reliable vaccination coverage survey estimates: Summary and recommendations from the "Meeting to share lessons learnt from the roll-out of the updated WHO Vaccination Coverage Cluster Survey Reference Manual and to set an operational research agenda around vaccination coverage surveys", Geneva, 18-21 April 2017. Vaccine 2018;36:5150-9.

19. Khan A. Childhood Immunization in Pakistan. Research and Development Solutions, 2012. Policy Briefs Series No 3.

20. Babirye JN, Engebretsen IMS, Makumbi F, et al. Timeliness of childhood vaccinations in Kampala Uganda: a community-based cross-sectional study. PLoS One 2012;7:e35432.

21. Schoeps A, Ouédraogo N, Kagoné M, et al. Socio-Demographic determinants of timely adherence to BCG, Penta3, measles, and complete vaccination schedule in Burkina Faso. Vaccine 2013;32:96-102.

22. National Institute of Population Studies (NIPS) [Pakistan] and ICF International. Pakistan demographic and health survey 2012-13. Islamabad, Pakistan, and Calverton, Maryland, USA: NIPS and ICF International, 2013.

23. King G, Zeng L. Logistic regression in rare events data. Polit Anal 2001;9:137-63.

24. Dansereau E, Brown D, Stashko L, et al. A systematic review of the agreement of recall, home-based records, facility records, BCG scar, and serology for ascertaining vaccination status in low and middleincome countries [version 1; peer review: 1 approved, 1 approved with reservations]. Gates Open Res 2019;3.

25. Brown DW, Gacic-Dobo M. Home-Based record prevalence among children aged 12-23 months from 180 demographic and health surveys. Vaccine 2015;33:2584-93.

26. Brown DW, Gacic-Dobo M. Occurrence of home-based record stock-outs - A quiet problem for national immunization programmes continues. Vaccine 2018;36:773-8.
27. Oliver-Williams C, Brown E, Devereux S, et al. Using mobile phones to improve vaccination uptake in 21 low- and middle-income countries: systematic review. JMIR Mhealth Uhealth 2017;5:e148.

28. Masters NB, Wagner AL, Boulton ML. Vaccination timeliness and delay in low- and middle-income countries: a systematic review of the literature, 2007-2017. Hum Vaccin Immunother 2019;48:1-16.

29. Centers for Disease Control and Prevention (CDC). Timing and spacing of immunobiologics, 2019. Available: https://www.cdc.gov/ vaccines/hcp/acip-recs/general-recs/timing.html\#t-01

30. Pan American Health Organization (PAHO). Tools for monitoring the coverage of integrated public health interventions. vaccination and deworming of soil-transmitted helminthiasis. Washington, D.C: $\mathrm{PAHO}, 2017$. https://www.paho.org/hq/index.php?option=com content\&view =article\&id=278:im-publications\&ltemid=39427\&lang= en

31. Wiese-Posselt M, Reiter S, Gilsdorf A, et al. Needs and obstacles of uniform immunisation schedules in the European Union. Bundesgesundheitsblatt Gesundheitsforschung Gesundheitsschutz 2009;52:1099-104

32. Odutola A, Afolabi MO, Ogundare EO, et al. Risk factors for delay in age-appropriate vaccinations among Gambian children. BMC Health Serv Res 2015;15:346.

33. Nisar MI, Ilyas M, Naeem K, et al. Cause of death in under 5 children in a demographic surveillance site in Pakistan. Online $J$ Public Health Inform 2017;9:e174.

34. Usman HR, Rahbar MH, Kristensen S, et al. Randomized controlled trial to improve childhood immunization adherence in rural Pakistan: redesigned immunization card and maternal education. Trop Med Int Health 2011;16:334-42.

35. Rakhshani NS, Tahir R, Ali F, et al. Increasing immunisation in Karachi, Pakistan: a feasibility and acceptability study of the vaccine indicator and reminder band community intervention, 3ie formative evaluation report. New Delhi: International Initiative for Impact Evaluation, 2019.

36. Higgins JPT, Soares-Weiser K, Reingold A. Systematic review of the non-specific effects of BCG, DTP and measles containing vaccines. WHO: Strategic Advisory Group of Experts on Immunization, 2014.

37. Lund N, Andersen A, Hansen ASK, et al. The effect of oral polio vaccine at birth on infant mortality: a randomized trial. Clin Infect Dis 2015;61:1504-11.

38. Gibson DG, Ochieng B, Kagucia EW, et al. Individual level determinants for not receiving immunization, receiving immunization with delay, and being severely underimmunized among rural Western Kenyan children. Vaccine 2015;33:6778-85.

39. World Health Organization (WHO). Suboptimal routine immunization coverage causing measles outbreaks, 2013. Available: http://www. emro.who.int/pak/pakistan-news/suboptimal-routine-immunizationcoverage-causing-measles-outbreaks.html

40. World Health Organization (WHO). Weekly epidemiological Bulletin: disease early warning system and response in Pakistan, 2013. Available: http://www.emro.who.int/images/stories/pakistan/ documents/pak_documents/DEWS/Weekly-Epidemiological-Bulletin35-04092013.pdf?ua=1

41. Gram L, Soremekun S, ten Asbroek A, et al. Socio-Economic determinants and inequities in coverage and timeliness of early childhood immunisation in rural Ghana. Trop Med Int Health 2014;19:802-11.

42. Kawakatsu Y, Tanaka J, Ogawa K, et al. Effects of three interventions and determinants of full vaccination among children aged 12-59 months in Nyanza Province, Kenya. Public Health 2015;129:1530-8. 